\title{
Sub Cutanuous Hemangiosarcoma in Sheep in Basrah Province
}

\author{
R. M. N. Hussein \\ Coll.of Vet.Med./Uive.of Basrah
}

\begin{abstract}
Sub cutanuous tumor in a domestic lamb,2 weeks old, and tumor was surgically removed, histopathological diagnosis confirmed to be hemangiosarcoma. Its appeared low grade malignancy, after the surgical operation, the animal is in good condition, no signs of recurrent tumor.
\end{abstract}

\section{Introduction}

Hemangiosarcoma is a malignant and aggressive tumor affected cells that line blood vessels (endothelial cells) (1) and (2), its name comes from hemangi, which mean blood vessels and sarcoma which means malignant tumor(3).It is insidious, as it attempts to build its own blood vessels network, making blood blister like formation which disrupts normal organ function.( 4).t can theoretically arise from any tissue where there are blood vessels (which amount to anywhere in the body) (5) and (2), but there are three classical locations which account for most presentations: dermal form (skin), hypodermal form (under the skin), and visceral form (splenic, cardiac). (4).It is highly metastasis and most forms of the disease are associated with poor prognosis. (4) and (6) Dermal hemangiosarcoma often appear as a dark to purple skin lesion which may be raised and appear on hairless areas like the abdomen.(4). Hypodermal hemangiosarcoma: can occur any where on the body and may appear as soft mass or be a firm invasive mass with ulceration (4). Sub cut hemangiosarcoma is typically larger than dermal hemangiosarcoma. (3). Visceral hemangiosarcoma accounts for $2 \%$ all reported malignancies. it is locally invasive and highly metastasis (4).

\section{Materials and methods}

The animal was young lamb, 2 weeks old; brown in color generally it is in good health. There was a mass suggesting tumor (fig.1).the mass was removed
Hemangiosarcoma is relatively common in dogs it's estimated that this type of cancer accounts for $5-7 \%$ of all tumor seen in dogs (7). Unlike other cancer, hemangiosarcoma is almost exclusive diseases of dogs, in people a similar type of tumor (angiosarcoma), yet angiosarcoma account for much less than $1 \%$ of all tumor seen in people. (7) The poor prognosis for a patient with non dermal hemangiosarcoma is based mainly on the metastatic rate, metastasis most often show up in the lung, omentum, liver, and mesentery, although metastatic nodules have been found in many other tissues of the body. (6).In dogs non visceral hemangiosarcoma occur commonly less than visceral hemangio-sarcoma. Cats develop hemangiosarcoma less frequently than dogs, and their tumors are usually non visceral. Hemangiosarcomas are rare in other animal species (8). The interaction of the heritable risk factors with the environment probably lead to the spectrum of mutation that give rise to the tumor its important to understand cancer is a genetic disease although its not always heritable (9).Treatment of subcutaneous hemangiosarcoma consists of surgical excision of the primary tumor and adjuvant chemotherapy. (5, 3and 9).

surgically. The mass was fixed in formalin, sections were cut, then paraffin blocks were prepared, slides were made and stained with Eosin and Hematoxylin. 


\section{Results}

\section{Macroscopically:}

The tumor was subcutaneously, measure about $5 \mathrm{~cm}$ in diameter fig(1), the

cut section showed hemorrhage suggesting vascular origin.

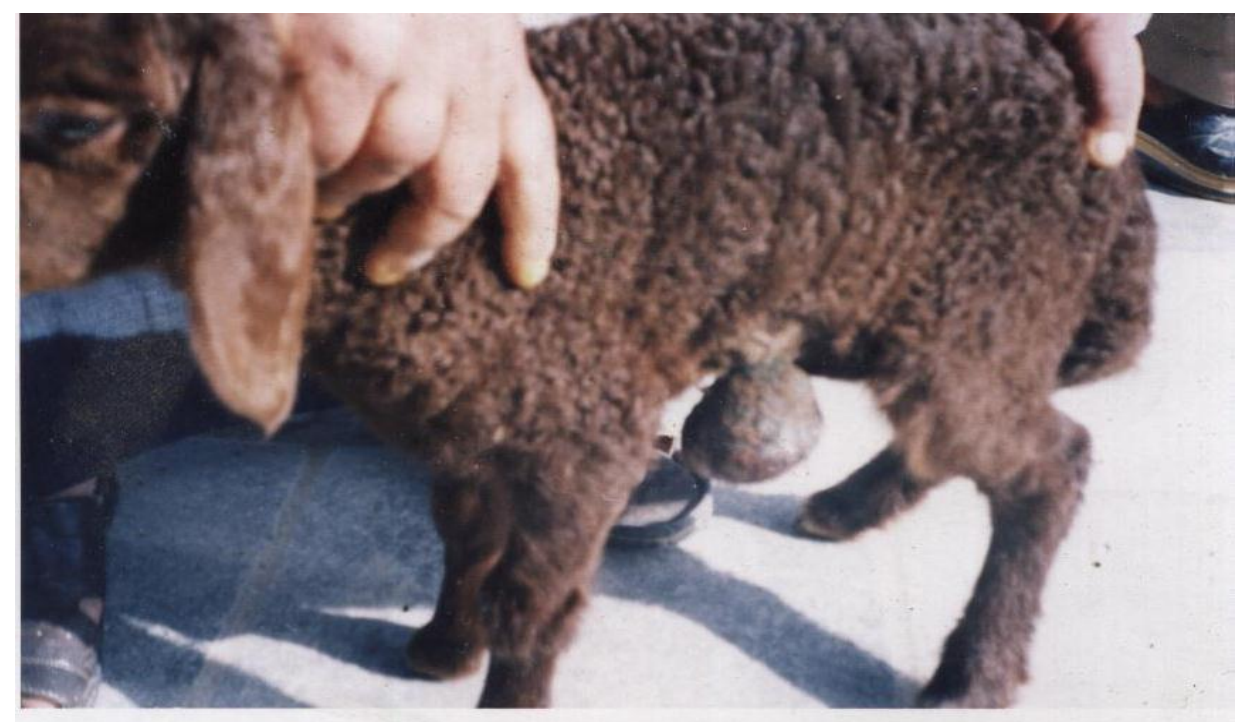

Fig (1): there was a mass in ventrolateral position in a lamb

\section{Microscopic examination:}

Histopathology of the mass showed to be tumor of vascular origin and it was mostly of malignant character and diagnosed as hemangiosarcoma, but it appear of low grade in character the tumor were not circumscribed, wide spread therefore suggestion that the tumor is not benign Fig $(2,3,4,5)$. The tumor was not well circumscribed, penetrating in the surrounding tissue, there was heavy concentration of varied sized blood vessels. Likes of varying size associated with areas of hemorrhage.As the initial examination the animal is survived after the operation for 18 months without recurrence of the tumor.

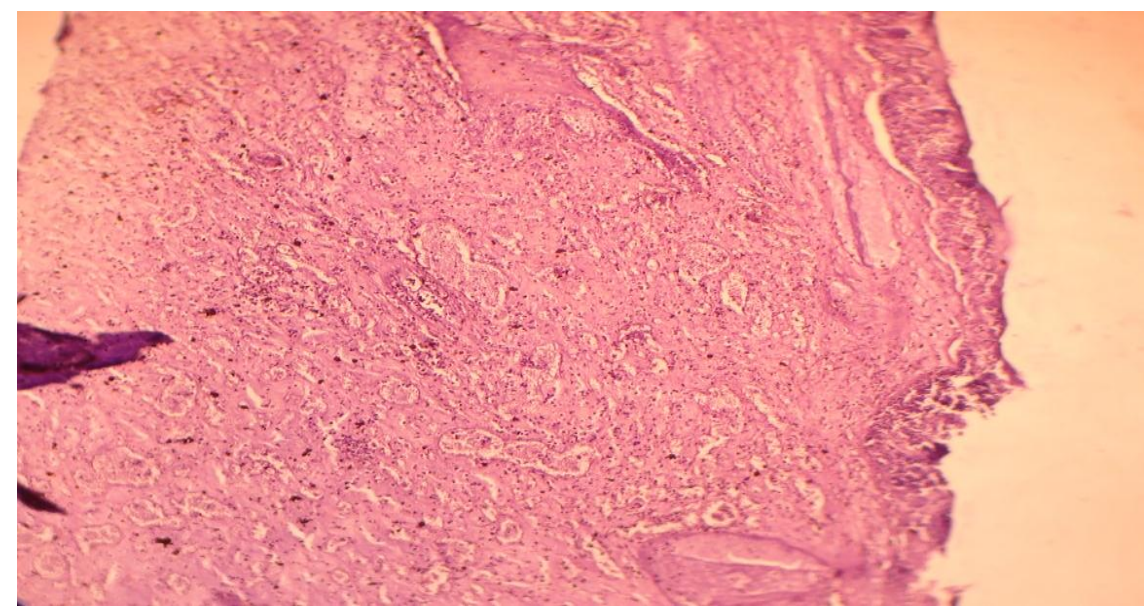

Fig (2): Histopathological section of tumor showing hemangiosarcoma under the skin (50X H\&E stain). 


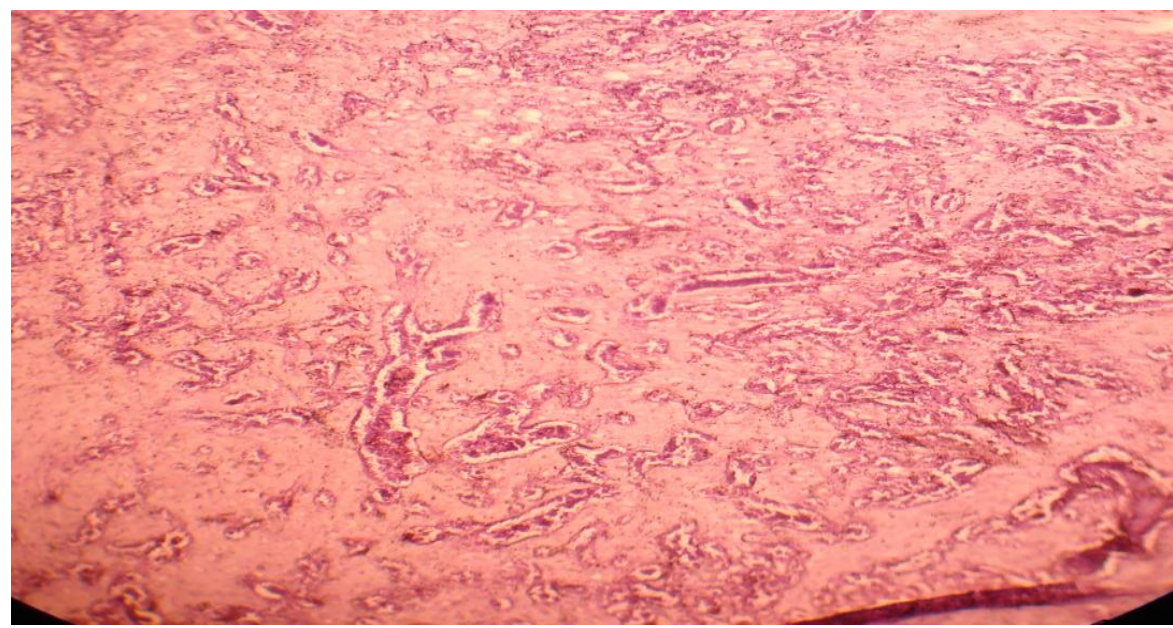

Fig.(3): histopathological section of tumor showed numerous blood spaces and small capillaries filled with red blood cell (125X H \& E stain).

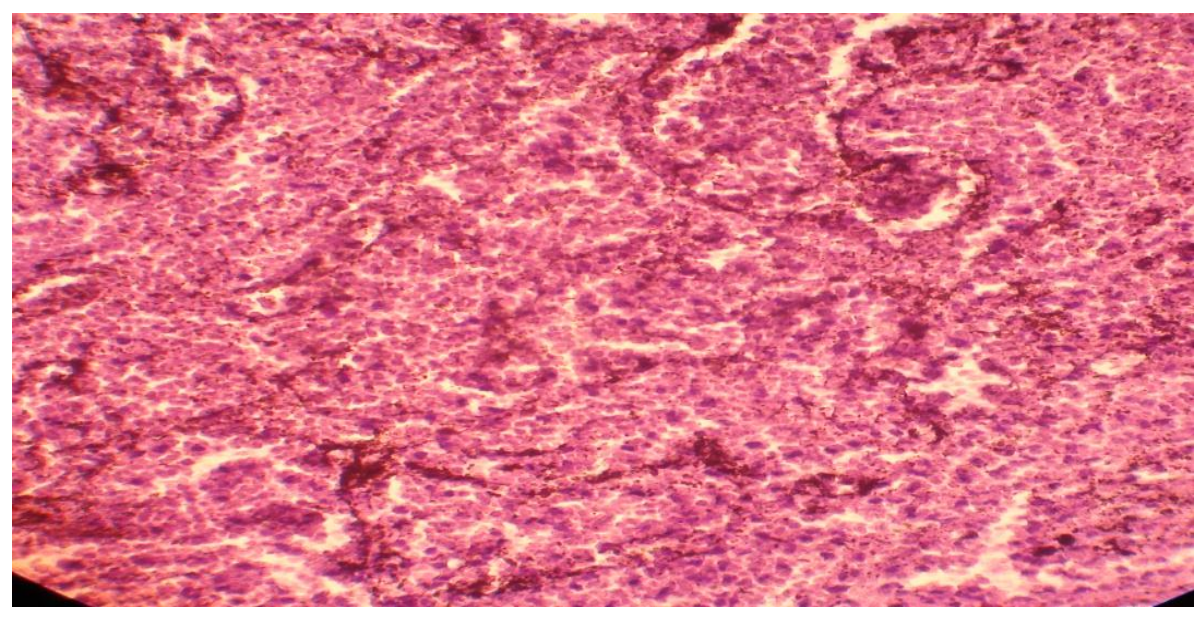

Fig. (4): histopathological section of tumor showed numerous blood spaces and small capillaries filled with red blood cell(500X H \& E stain).

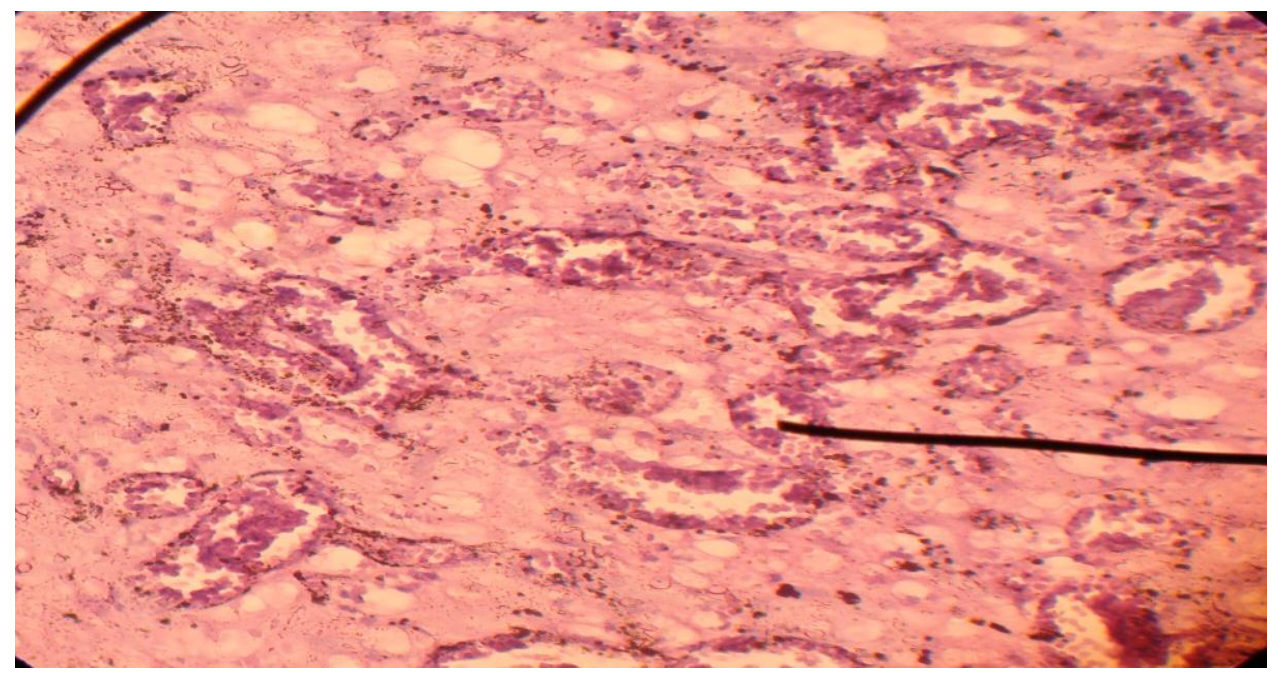

Fig. (5) histopathological section of tumor showed numerous blood spaces of small capillaries filled with red blood cell ( 500X H\& E stain). 


\section{Discussion}

The present case showed the tumor of low grade of malignancy, but in dogs the tumor is a highly malignant neoplasm (10). As the animal was did not showed sever clinical condition at the time of diagnosis and after the operation the animal was healthy and no secondary complication, and no signs of recurrence was present during 18 months, this result come in agreement with finding of (6) who reported that a case of subcutanuous hemangiosarcoma in a dog, the dog had not followed the expected course of progression of this disease (i.e. recurrence of tumor, metastatic disease ect.) during 8 month following the surgery. In the other hand this result comes in contrast with (4) which reported that hemangiosarcoma is highly metastasize and most of diseases are associated with poor prognosis, but the dermal form can potentially be cured by surgery alone.Also this result is come in contrast with the finding of (10) and (5). which reported that surgical removal alone has been associated with approximately 6 months (median survival time).Histopathological section of the tumor showed there was a heavy concentration of varied sized blood vessels, like of varying sizes associated with areas of hemorrhage this data is in accordance to findings of (7) which reported that generally the tumor cells retain some normal aspects of behavior, so they try to make blood vessels but these blood vessels are tortuous and malformed and blood cells tend to pool in them and clot. The clot then prevent blood and nutrients from reaching tumor cells, in turn causing them to die, this create some rupture in the tumor through which the blood may escape in sub cutanuous space.The tumor was not well circumscribed penetrating the surrounding tissue these result where in line with finding of (1) who reported sub cutanuous hemangiosarcoma poorly circumscribed and very invasive, the dermal hemangiosarcoma is well circumscribed and confined to the dermis.

\section{Conclusion}

Subcutaneous tumor in a kid showed hemangiosarcoma but there was in low grade of malignancy and no evidence of metastatic disease even histopathological characteristics where typical for malignant tumor. Up on reviewing the history of patient the animal survive for 18 months without recurrence of this tumor, unlike in dogs and cats given a highly aggressive nature of this neoplasm.

\section{References}

1.Hahn, K. A. (2001). Cutaneous hemangiosarcoma benign disease or not?. TUMOR TID BITS. 2(10). www.Gcvs.com

2.Smith, A. (2004). Hemangiosarcoma in dogs and cats. Vet Clin North Am Small Anim Pract. 33(3): 533553.

3.Hitti y. k. and Al-khatib a. (2005). Hitti`s New Medical dictionary. Dar Alkutub Al-aslami. English Arabic. Alkauthar print office. Beirut.

4.Clifford, C. A.; Makin. A. J. and Henry. C. T. (2000). Treatment of canine hemangiosarcoma 2000 and beyond. J Vet Intern Med. 14 (5) 479-485.
5.Sorenmo, K. V.; Jeglum, K. A. and helfand, S. C. (1993). Chemotherapy of canine hemangiosarcoma with doxorubicin and cyclophosphamide. J. Vet. Intern med. 7(6): 370-376.

6.Reed, L. A. and Flanders, J. (2003). Peripheral Vascular Lesion in a Weimaraner Arteriovenous fistula vs hemangiosarcoma. A senior seminar paper. College of vet medicine. Cornell university.

7.Modiano J. F.; Ritt G. M.; Breen M. and Breen T. (2006). Canine Hemangiosarcoma - the Road from Despair to Hope. Journal experimental hematology. 
8.Schultheiss, C. B.(2004). A retrospective study of visceral and non visceral hemangiosarcoma and hemangioma in domestic animals. J Vet Diagn Invest. 16: 522- 526.

9.Bulakowwski, E. J.; philibert, J. C.; Siegel, S.; Clifford, C. A. Risbon, R.; Zivin, K. and Cronin, K. L. (2008). Evaluation of outcome associated with sub cut and intramuscular hemangiosarcoma treated with adjuvant doxorubicin in dogs: 21cases (2001-2006). Journal of the American veterinary medical association 233(1): 122-128.

10. Heller, D. A.; Clifford, G. A.; Goldschidt, M. H.; Holt, D. E.; Manfred, M. J. and Sorenmo, K. V. (2005). BRIEF COMMUNICATIONS and CASE REPORTS: Assessment of Cyclooxygenase-2 Expression in Canine Hemangiosarcoma, Histocytic Sarcoma, and Mast cell tumor. Vet Pathol 42: 350353.

\section{غرن وعائي في الاغنام في محافظة البصرة}

$$
\text { كلية الطب البيطري/ جامعة البصرة }
$$

\section{الخلاصة}

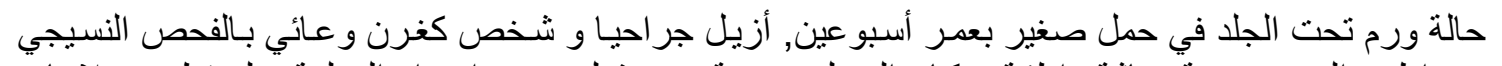

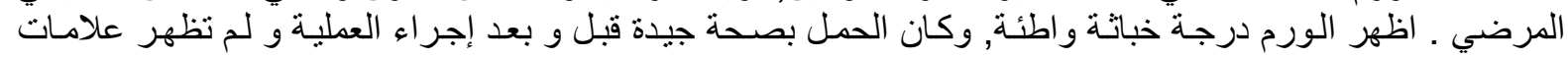
رجوع الأورم بعد إجر اء العملية. 